\title{
Clinical and laboratory assessment of patients with new-onset atrial fibrillation in acute myocardial infarction
}

\author{
Monika Raczkowska-Golanko ${ }^{1}{ }^{\circ}$, Ludmiła Daniłowicz- \\ -Szymanowicz ${ }^{2}$, Radosław Nowak ${ }^{2}$, Wiesław Puchalski ${ }^{3}$, \\ Marcin Gruchała ${ }^{3}{ }^{\circ}$, Dariusz Kozłowski ${ }^{2}{ }^{\circ}$, Grzegorz Raczak ${ }^{2}$
}

\author{
${ }^{1}$ Clinical Centre of Cardiology, University Clinical Centre, Gdańsk, Poland \\ 2 II Department of Cardiology, Medical University of Gdańsk, Poland \\ ${ }^{3}$ I Department of Cardiology, Medical University of Gdańsk, Poland
}

\begin{abstract}
Background: New-onset atrial fibrillation (NOAF) is one of the complications of acute myocardial infarction (AMI), and is associated with poor outcome. The aim of the study was clinical and laboratory assessment of patients with NOAF in AMI. Material and methods: This is a retrospective, single-centre study of AMI patients with NOAF, who were admitted to Clinical Centre of Cardiology of the University Clinical Centre in Gdansk, from January 2016 to June 2018. The medical history, echocardiography parameters, AMI localization and infarcted-related artery as well as laboratory parameters at the admission and at the moment of NOAF onset were taken into further analyses. Results: From 1155 consecutive AMI patients 103 (8.9\%) with NOAF were enrolled into the study. A significant increase in C-reactive protein (CRP) and high-sensitive Troponine I (hsTnl) level, whereas significant decrease in potassium and hemoglobin level was observed at the moment of NOAF in comparison to admission. Conclusions: Our study suggests that markers of inflammation (CRP), myocardial necrosis (hsTnl), hemoglobin and serum potassium may be associated with NOAF in the setting on AMI. The aforementioned parameters are generally available and may be used as an inexpensive and rapid way to select patients who are at high risk of developing NOAF.

Keywords: atrial fibrillation • acute myocardial infarction • NOAF
\end{abstract}

\section{Citation}

Raczkowska-Golanko M, Daniłowicz-Szymanowicz L, Nowak R, Puchalski W, Gruchała M, Kozłowski D, et al. Clinical and laboratory assessment of patients with new-onset atrial fibrillation in acute myocardial infarction. Eur J TransI Clin Med 2018;1(1):39-43. • DOI: 10.31373/ejtcm/95256

\section{Introduction}

Atrial fibrillation (AF) is the most common arrhythmia that is characterized by irregular and rapid activation in the atria without $\mathrm{P}$ waves in the electrocardio- gram (ECG). In various countries around the world AF prevalence is estimated at $3 \%$ of adults aged 20 years or older [1]. The most significant risk factor for AF is age, although female sex, diabetes mellitus (DM), smoking, body mass index (BMI), alcohol consumption, hyperten-

Corresponding author:

Monika Raczkowska-Golanko, Clinical Centre of Cardiology, University Clinical Centre, Gdańsk, 7 Dębinki, 80-952 Gdansk, Poland,

e-mail: mraczkowskagolanko@gmail.com

Available online: ejtcm.gumed.edu.pl

Copyright $® \quad$ Medical University of Gdańsk

This is Open Access article distributed under the terms of the Creative Commons Attribution-ShareAlike 4.0 International (CC BY-SA 4.0); license available at: https:// creativecommons.org/licenses/by-sa/4.0/. 
sion treatment, systolic blood pressure, heart failure, left ventricular hypertrophy and myocardial infarction also were identified [2]. The $\mathrm{CHA}_{2} \mathrm{DS}_{2}$-VASc score is used to estimate the risk of stroke in patients with $\mathrm{AF}$ and to guide prophylactic treatment. According to this score, patients with AF but without clinical risk factors for stroke do not need antithrombotic therapy, but oral anticoagulation is strongly recommended for patients with $\geq 1$ risk factors [3] with a substantial increase in stroke and systemic thromboembolism. Strokes related to AF are associated with higher mortality, greater disability, longer hospital stays, and lower chance of being discharged home than strokes unrelated to AF.

According to the literature, AF coincides in 6-21\% patients with acute myocardial infarction (AMI) [4]. It is well known that $A F$ is connected with adverse outcomes in AMI [5]. Moreover, AF is independent risk factor of increased long-term mortality, regardless if $A F$ is a primary or secondary diagnosis during hospitalization [6]. As in the general population, AF in AMI is associated with increased risks of cardiovascular and cerebrovascular complications [7]. Similiarly, in patients with AMI advanced age, heart failure, higher BMI, DM, and depression of left ventricular function are the risk factors of $A F$, but there are still some predictors which are not clearly defined in patients with AMI $[2,4]$. Furthermore, there is no scoring system dedicated to assessing the risk of new-onset AF (NOAF) in patients who are having an AMI.

The knowledge about the pathogenesis of AF in the setting of $A M I$ is still evolving. Due to the fact that $A F$ is an independent predictor of mortality after $\mathrm{AMI}$, the aim of our study was to conduct clinical and laboratory assessment of patients with NOAF in AMI and to define predictors of NOAF in the setting of AMI.

\section{Material and methods}

This single-centre retrospective study enrolled 103 consecutive patients with NOAF from 1155 patients hospitalized in 4 cardiology units between January 2016 and June 2018 due to AMI. 418 of those patients had ST segment elevation myocardial infarction (STEMI) and 737 had non-ST elevation myocardial infarction (NSTEMI). Data was collected through MedStream Designer (Transition Technologies, Poland) which was fully integrated with the hospital information system. The diagnosis of STEMI was made based on acute chest pain and ST-segment elevation. All of the patients had a 12lead ECG acquired and interpreted as soon as possible. The diagnosis of NSTEMI was based on the serum markers of myocardial necrosis [8].

Diagnosis of $A F$, defined as irregular RR intervals and the absence of $P$ waves lasting for $\geq 30$ seconds, was based on physician interpretation of ECG. The term
NOAF was applied to any newly diagnosed AF that appeared during the index hospitalization, irrespective of the duration of the arrhythmia. All the patients then had continuous ECG monitoring in the cardiac intensive care unit, afterwards they had 12-lead ECG performed daily during their hospital admission. The exclusion criteria were: $<18$ years of age and history of prior AF or atrial flutter.

The medical history (prior MI, revascularization, hypertension, diabetes, smoking), echocardiographic parameters (left ventricular ejection fraction [LVEF], left atrium size [LA], presence of mitral regurgitation $[\mathrm{MR}]$ ), laboratory parameters (brain natriuretic peptide [BNP], C-Reactive Protein [CRP], high-sensitive Troponin I [hsTnl], creatine kinase muscle-brain, complete blood count, hemoglobin [Hgb], leucocytes, neutrophils, glucose, serum potassium) at the admission and the moment of NOAF onset were taken into further analyses. The incidence of in-hospital mortality was also taken into consideration.

Coronary angiography and percutaneous coronary angioplasty $(\mathrm{PCl})$ were performed according to standard practice in every patient. Coronary blood flow assessed during $\mathrm{PCl}$ was determined according to Thrombolysis in Myocardial Infarction (TIMI) classification. All angiograms were ranked as to the number of diseased major branches of coronary arteries. We classified a coronary artery as 'diseased' if there was any obstructive lesion $\geq 30 \%$ of that artery's diameter.

Patients were treated with anti-thrombotic agents, beta-blockers and angiotensin converting enzyme (ACE) inhibitors or angiotensin receptor blockers (ARBs) and cholesterol-lowering agents according to contemporary guidelines [9-10].

The protocol of the study was approved by the local bioethics commmittee.

\section{Statistical analysis}

Continuous data are presented as median $\left(25^{\text {th }}-75^{\text {th }}\right.$ percentile), while categorical data are expressed in proportion. We performed the Shapiro-Wilk test to check whether our data were normally distributed. Majority of the analysed parameters did not have a normal distribution, even after logarithmic data transformation. Thus, we selected appropriate statistical analysis methods based on non-parametric tests: comparison of laboratory results upon admission and at the moment of NOAF onset was performed with Wilcoxon matchedpairs test. The statistical analysis was performed using STATISTICA 9.0 (StatSoft, Tulsa OK, USA) package and R 2.15.2 environment. 


\section{Results}

Table 1. Demographic, clinical and laboratory data of the studied group

\begin{tabular}{|c|c|}
\hline & $\begin{array}{l}\text { NOAF patients } \\
n=103\end{array}$ \\
\hline Age, years * & $72(64-82)$ \\
\hline Male, $\mathrm{n}(\%)$ & $64(62 \%)$ \\
\hline Hypertension, n (\%) & $72(70 \%)$ \\
\hline Diabetes mellitus, $\mathrm{n}(\%)$ & $32(31 \%)$ \\
\hline Active smoker, n (\%) & $30(30 \%)$ \\
\hline Former smoker, n (\%) & $53(51 \%)$ \\
\hline $\mathrm{BMI}, \mathrm{kg} / \mathrm{m}^{2}$ & $27(24-30)$ \\
\hline Previous MI/PCI/CABG, n (\%) & $39(38 \%)$ \\
\hline Previous ASA, $\mathrm{n}(\%)$ & $46(45 \%)$ \\
\hline Previous ACEI/ARB, n (\%) & $53(51 \%)$ \\
\hline Previous statins, $\mathrm{n}(\%)$ & $40(39 \%)$ \\
\hline In-hospital death, $\mathrm{n}(\%)$ & $16(16 \%)$ \\
\hline Hospitalization time, days $*$ & $10(7-18)$ \\
\hline Development of NOAF, day * & $1(1-3)$ \\
\hline STEMI, $\mathrm{n}(\%)$ & $37(36 \%)$ \\
\hline NSTEMI, n (\%) & $66(64 \%)$ \\
\hline $\mathrm{BNP}, \mathrm{pg} / \mathrm{ml} *$ & $371(168-1064)$ \\
\hline Creatinine, $\mathrm{mg} / \mathrm{ml} *$ & $0.96(0.81-1.31)$ \\
\hline Glucose, $\mathrm{mg} / \mathrm{dl} *$ & $153(121-216)$ \\
\hline Total cholesterol, mg/dl * & $168(131-193)$ \\
\hline High density lipoprotein, $\mathrm{mg} / \mathrm{dl} *$ & $41(33-52)$ \\
\hline Low density lipoprotein, $\mathrm{mg} / \mathrm{dl} *$ & $94(71-121)$ \\
\hline Triglyceride, $\mathrm{mg} / \mathrm{dl} *$ & $108(76-145)$ \\
\hline C-reactive protein, $\mathrm{mg} / \mathrm{l} *$ & $12.3(3.3-36.1)$ \\
\hline hsTnI, ng/ml * & $0.49(0.07-4.08)$ \\
\hline CK-MB, $\mathrm{ng} / \mathrm{ml} *$ & $4.8(2.2-14.6)$ \\
\hline Hemoglobin, g/dl * & $13.3(12.2-14.5)$ \\
\hline Leukocytes, $x 10 \backslash \wedge 9 / / *$ & $10.6(7.9-14.2)$ \\
\hline Neutrophil/lymphocyte ratio * & $3.8(2.2-6.0)$ \\
\hline $\mathrm{K}, \mathrm{mmol} / \mathrm{l} *$ & $4.3(3.9-4.6)$ \\
\hline
\end{tabular}

* data are presented as median $\left(25^{\text {th }}-75^{\text {th }}\right.$ percentile) Abbreviations: $\mathrm{Ml}-$ myocardial infarction; $\mathrm{PCl}$ - percutaneous coronary angioplasty; CABG - coronary artery bypass graft;

ASA - acetylsalicylic acid; ACEI - angiotensin converting enzyme inhibitor; ARB - angiotensin receptor blocker, NOAF - new-onset atrial fibrillation; STEMI - ST-segment-elevation myocardial infarction; NSTEMI - non-ST-segment-elevation myocardial infarction; BNP - brain natriuretic peptide; CRP - C-Reactive Protein; hsTnl - high sensitive Troponine I; CK-MB - creatine kinase-muscle/brain; $\mathrm{K}$ - serum potassium
After applying the exclusion criteria, the final study cohort comprised a total of 103 patients with AMI, with no prior history of AF and who developed NOAF. From this group more than a half patients had NSTEMI. The overall incidence of NOAF was $8,9 \%(n=103)$ of the enrolled study population ( $n=1155)$, the mean age was 72 years, and more than a half of group were male. Most of the patients developed the NOAF in the first day of the admission ( $n=65$ ), 28 patients developed the NOAF between second and fifth day of the index hospitalization, 10 patients developed after the fifth day.

A total of 16 patients died during the analyzed hospital stays: $69 \%(n=11)$ died due to cardiologic complications, 2 due to sepsis, 1 due to hemorrhagic stroke and 2 from other reasons. The demographic, clinical data and laboratory results (upon admission) of the studied group are summarized in Table 1.

Table 2. Angiographic and echocardiographic findings

\begin{tabular}{|c|c|}
\hline \multicolumn{2}{|l|}{$\begin{array}{l}\text { NOAF patients } \\
n=103\end{array}$} \\
\hline \multicolumn{2}{|c|}{ Infarct-related artery in coronary angiography } \\
\hline$L M, n(\%)$ & $1(1 \%)$ \\
\hline LAD, n (\%) & $23(22 \%)$ \\
\hline $\mathrm{RCA}, \mathrm{n}(\%)$ & $24(24 \%)$ \\
\hline LCX, n (\%) & $22(21 \%)$ \\
\hline Others, n (\%) & $10(10 \%)$ \\
\hline $\begin{array}{l}\text { Multi-vessel coronary artery disease, } \\
\mathrm{n}(\%)\end{array}$ & $5(5 \%)$ \\
\hline TIMI 3 & $71(70 \%)$ \\
\hline \multicolumn{2}{|l|}{ Echocardiography } \\
\hline LVEF, \%* & $42(33-50)$ \\
\hline LA diameter, mm* & $41(37-44)$ \\
\hline \multicolumn{2}{|l|}{ Mitral regurgitation } \\
\hline Mild, n (\%) & $70(70 \%)$ \\
\hline Moderate, n (\%) & $25(24 \%)$ \\
\hline Severe, n (\%) & $8(8 \%)$ \\
\hline
\end{tabular}

* data are presented as median $\left(25^{\text {th }}-75^{\text {th }}\right.$ percentile) Abbreviations: LM - left main artery; LAD - left anterior descending artery; RCA - right coronary artery; LCX - left circumflex artery; LVEF - left ventricular ejection fraction

Table 3. Laboratory parameters upon admission and at the moment of NOAF which are statistically significant or borderline

\begin{tabular}{|c|c|c|c|}
\hline & $\begin{array}{c}\text { On admission } \\
n=103\end{array}$ & $\begin{array}{c}\text { NOAF onset } \\
n=103\end{array}$ & $\mathbf{P}$ \\
\hline C-reactive protein, mg/l & $12.3(3.3-36.1)$ & $30.4(5.7-110.6)$ & $<0.0001$ \\
\hline hsTnI, ng/ml & $0.49(0.07-4.08)$ & $0.86(0.08-8.29)$ & $<0.0001$ \\
\hline CK-MB, ng/ml & $4.8(2.2-14.6)$ & $25.9(12.1-97.7)$ & 0.083 \\
\hline Hemoglobin, g/dl & $13.3(12.2-14.5)$ & $12.9(11.4-14.0)$ & $<0.0001$ \\
\hline Leukocytes, x10\^9/I & $10.6(7.9-14.2)$ & $10.3(8.1-14.6)$ & 0.164 \\
\hline Neutrophil/lymphocyte ratio & $3.8(2.2-6.0)$ & $7.2(5.2-10.1)$ & 0.110 \\
\hline $\mathrm{K}, \mathrm{mmol} / \mathrm{l}$ & $4.3(3.9-4.6)$ & $4.1(3.8-4.5)$ & $<0.013$ \\
\hline
\end{tabular}

* data are presented as median $\left(25^{\text {th }}-75^{\text {th }}\right.$ percentile)

Abbreviations: CRP - C-Reactive Protein; hsTnl - high sensitive Troponin I; CK-MB - creatine kinase-muscle/brain; K- serum potassium 
The angiographic, echocardiographic characteristics of the studied group are presented in Table 2. All of the laboratory parameters withdrawn on admission and at the moment of NOAF, which are statistically significant (or borderline significant) are presented in Table 3.

\section{Discussion}

The major finding of this study is that markers of inflammation (CRP), myocardial necrosis (hsTnl), Hgb and serum potassium may be associated with NOAF in the setting of AMI. These simple, inexpensive parameters could be helpful in identification patients with higher risk of NOAF.

Our results confirm the role of the CRP-AF correlation which was demonstrated in prior studies [11-12]. However, there are still discussions about the role of CRP in the pathogenesis of myocardial infarction [13]. There is also a possibility that patients with $\mathrm{AMI}$ are more likely to develop inflammation, which may promote AF. Moreover, neutrophil/lymphocyte ratio, which is also a reflection of systemic inflammatory status, is also described as a predictive factor of NOAF [14]. Our results did not confirm that hypothesis, however our analysis was not restricted to just patients with STEMI as in the previously the aforementioned article.

Zhu et al recently established that hsTnl level is an independent predictor of AF incidents. Our results are similar, however we only claim the association between the increase of hsTnl and outcome of NOAF [15]. We found a similar increase in the level of CK-MB, but it was not statistically siginificant. In another study, Parashar et al denied the connection between another factor of myocardial necrosis - Troponin $\mathrm{T}[\mathrm{TnT}]$ and the occurrence of NOAF [12]. However we analyzed the increase of hsTnl level between the hospital admission and day of NOAF, whereas Parashar et al measured the level of TnT only once.

Another predictive factor is the level of hemoglobin. Our study suggests that NOAF onset is associated with a decrease in hemoglobin level. The literature on this subject is inconsistent. For example, Distelmaier et al. demonstrated a statistically significant relationship between elevated levels of $\mathrm{Hgb}$ and occurrence of AF after AMI [16]. This might be due to the fact that they compared the level of $\mathrm{Hgb}$ between the NOAF after AMI patient group and matched controls [16]. In contrast, we analyzed the changes in Hgb level during the index hospitalization within the patient group only.

Several studies previously investigated the influence of potassium in the development of AF [17-19]. It is a well-known fact, that lower levels of serum potassium were associated with a higher risk of AF. We demonstrated that a decreasing level of serum potassium after AMI may be also the connected with NOAF.

There are a lot of echocardiographic parameters of $A F$, e.g. the parameters of systolic and diastolic LV function, as well as the LA parameters [20-23]. In our data, the LVEF value was below references range for healthy people. There were no data of LAVI, only LA diameter due to retrospective character of our study. Moreover, the Framingham Heart Study proved that every 5-mm increase in LA diameter increased the occurrence of AF by $39 \%$ while the Cardiovascular Health Study showed more than a double-fold increase in the developing NOAF when LA diameter $>40 \mathrm{~mm}$ [22-23].

It should be noted that there are some limitations of the study. First of all, this was a single-centre retrospective study with a relatively small sample size. We did not analyze the entire hospitalized population with AMI to find the differences between those groups. Moreover, we do not have data on the duration of AF.

\section{Conclusions}

Our study suggests that markers of inflammation (CRP), myocardial necrosis (hsTnl), potassium and Hgb may be associated with NOAF in the setting on AMI. The aforementioned parameters are generally available and may be used as an inexpensive and rapid way to select patients who are at a high risk of developing NOAF. Further studies should be performed to design a dedicated scoring system for patients who are at risk of developing NOAF in the setting of AMI.

\section{References}

1. Haim M, Hoshen M, Reges O, Rabi Y, Balicer R, Leibowitz M. Prospective National Study of the Prevalence, Incidence, Management and Outcome of a Large Contemporary Cohort of Patients With Incident Non-Valvular Atrial Fibrillation. J Am Heart Assoc. 2015;4(1):e001486e001486.

2. Schnabel RB, Yin X, Larson MG, Magnani JW, Ellinor PT, Philip A, et al. Fifty-Year Trends in Atrial Fibrillation Prevalence, Incidence, Risk Factors, and Mortality in the Community. Lancet (London, England). 2015;386(9989): 154-62.

3. GH L, DA L. Stroke prevention in atrial fibrillation: A systematic review. JAMA. 2015;313(19):1950-62. 
4. Schmitt J, Duray G, Gersh BJ, Hohnloser SH. Atrial fibrillation in acute myocardial infarction: A systematic review of the incidence, clinical features and prognostic implications. Eur Heart J. 2009;30(9):1038-45.

5. Batra G, Svennblad B, Held C, Jernberg T, Johanson P, Wallentin L, et al. All types of atrial fibrillation in the setting of myocardial infarction are associated with impaired outcome. Heart. 2016;102(12):926-33.

6. Andersson T, Magnuson A, Bryngelsson I-L, Frøbert O, Henriksson KM, Edvardsson N, et al. All-cause mortality in 272186 patients hospitalized with incident atrial fibrillation 1995-2008: a Swedish nationwide long-term case-control study. Eur Heart J. 2013;34(14):1061-7.

7. Wolf $\mathrm{P}$ a, Abbott RD, Kannel WB. Original Contributions Atrial Fibrillation as an Independent Risk Factor for Stroke : The Framingham Study. Stroke. 1991;22:983-8.

8. Ibanez B, James S, Agewall S, Antunes MJ, Bucciarelli-Ducci C, Bueno H, et al. 2017 ESC Guidelines for the management of acute myocardial infarction in patients presenting with ST-segment elevation. Eur Heart J. 2018;39(2):119-77.

9. Hamm CW, Bassand JP, Agewall S, Bax J, Boersma E, Bueno H, et al. ESC Guidelines for the management of acute coronary syndromes in patients presenting without persistent ST-segment elevation. Eur Heart J. 2011;32(23):2999-3054.

10. Roffi M, Patrono C, Collet J-P, Mueller C, Valgimigli M, Andreotti F, et al. 2015 ESC Guidelines for the management of acute coronary syndromes in patients presenting without persistent ST-segment elevation. Eur Heart J. 2016;37(3):267-315.

11. Aronson D, Boulos M, Suleiman A, Bidoosi S, Agmon Y, Kapeliovich M, et al. Relation of C-Reactive Protein and New-Onset Atrial Fibrillation in Patients With Acute Myocardial Infarction. Am J Cardiol. 2007;100(5):753-7.

12. Parashar S, Kella D, Reid KJ, Spertus JA, Tang F, Langberg J, et al. New-Onset Atrial Fibrillation after Acute Myocardial Infarction and its Relationship to Admission Biomarkers [From the TRIUMPH Registry]. Am J Cardiol. 2013;112(9):1390-5.

13. Fordjour PA, Wang $Y$, Shi $Y$, Agyemang K, Akinyi M, Zhang $Q$, et al. Possible mechanisms of C-reactive protein mediated acute myocardial infarction. Eur J Pharmacol. 2015;760:72-80.

14. Wagdy S, Sobhy M, Loutfi M. Neutrophil/Lymphocyte Ratio as a Predictor of In-Hospital Major Adverse Cardiac Events, New-Onset Atrial Fibrillation, and No-Reflow Phenomenon in Patients with ST Elevation Myocardial Infarction. Clin Med Insights Cardiol. 2016;10:19-22.

15. Zhu K, Hung J, Divitini M, Murray K, Lim EM, St John A, et al. High-sensitivity cardiac troponin I and risk of incident atrial fibrillation hospitalisation in an Australian community-based cohort: The Busselton health study. Clin Biochem. 2018;58:20-5.

16. Distelmaier K, Maurer G, Goliasch G. Blood count in new onset atrial fibrillation after acute myocardial infarction - A hypothesis generating study. Indian J Med Res. 2014;139(4):579-84.

17. Krijthe BP, Heeringa J, Kors JA, Hofman A, Franco OH, Witteman JCM, et al. Serum potassium levels and the risk of atrial fibrillation: The Rotterdam Study. Int J Cardiol. 2013;168(6):5411-5.

18. Campbell NG, Allen E, Sanders J, Swinson R, Birch S, Sturgess J, et al. The impact of maintaining searum potassium $\geq 3.6 \mathrm{mEq} / \mathrm{Lvs} \geq 4.5 \mathrm{mEq} / \mathrm{L}$ on the incidence of new-onset atrial fibrillation in the first 120 hours after isolated elective coronary artery bypass grafting - study protocol for a randomised feasibility trial for th. Trials. 2017;18(1):1-9.

19. Madias JE, Patel DC, Singh D. Atrial fibrillation in acute myocardial infarction: a prospective study based on data from a consecutive series of patients admitted to the coronary care unit. Clin Cardiol. 1996;19(3):180-6.

20. Jons C, Joergensen RM, Hassager C, Gang UJ, Dixen U, Johannesen A, et al. Diastolic dysfunction predicts new-onset atrial fibrillation and cardiovascular events in patients with acute myocardial infarction and depressed left ventricular systolic function: a CARISMA substudy. Eur J Echocardiogr. 2010;11(7):602-7.

21. Nagueh SF, Appleton CP, Gillebert TC, Marino PN, Oh JK, Smiseth OA, et al. Recommendations for the Evaluation of Left Ventricular Diastolic Function by Echocardiography. J Am Soc Echocardiogr. 2009;22(2):107-33.

22. Vaziri SM, Larson MG, Benjamin EJ, Levy D. Echocardiographic predictors of nonrheumatic atrial fibrillation. The Framingham Heart Study. Circulation. 1994;89(2):724-30.

23. Psaty BM, Manolio TA, Kuller LH, Kronmal RA, Cushman M, Fried LP, et al. Incidence of and Risk Factors for Atrial Fibrillation in Older Adults. Circulation. 1997;96(7):2455-61. 